\title{
O PROCESSO DE BOLONHA E A INTENSIFICAÇÃO DO TRABALHO NA UNIVERSIDADE: ENTREVISTA COM JOSEP M. BLANCH*
}

\author{
LUCÍDIO BiANCHETTI ${ }^{* *}$
}

\begin{abstract}
RESUMO: Este texto, dividido em duas partes, focaliza o Processo de Bolonha e suas repercussóes sobre o trabalho dos professores de universidades europeias, com destaque para o processo de intensificação do trabalho desses docentes. Similarmente ao ocorrido no Brasil, a partir do predomínio do chamado "Modelo CAPES de Avaliação e Fomento", os professores europeus sentem o peso e os efeitos do denominado "produtivismo acadêmico". A parte central do texto reproduz entrevista concedida pelo professor Josep M. Blanch, ${ }^{1}$ da Universidade Autônoma de Barcelona (UAB). Suas reflexões e revelações a respeito da implementação de Bolonha na $\mathrm{UAB}$, em particular, e nas universidades europeias, em geral, servem como efeito-demonstração da implantação e da (pré)visualização dos resultados de um processo caracterizado pela heteronomia. Também compóe o texto uma breve apresentação, por meio da qual se visa contextualizar a temática da entrevista.
\end{abstract}

Palavras-chave: Processo de Bolonha. Intensificação do trabalho docente. Produtivismo acadêmico.

Entrevista realizada no contexto do projeto de estágio pós-doutoral: "Pesquisadores sob pressão: aproximações entre as exigências e as decorrências do modelo CAPES de avaliação e fomento e o Pacto de Bolonha" (2009-2010), na Faculdade de Psicologia e Ciências da Educação da Universidade do Porto (Portugal), com bolsa da CAPES, sob a supervisão do prof. dr. José Alberto Correia. A tradução da entrevista do espanhol para o português foi feita pelo próprio entrevistador.

** Doutor em História e Filosofia da Educação e professor associado no Centro de Ciências da Educação da Universidade Federal de Santa Catarina. E-mail: lucidio.bianchetti@pq.cnpq.br 
The Bologna Process and the intensification of University PROFESSORS' WORK: INTERVIEW WITH JOSEP M. BLANCH

ABSTRACT: This text, divided in two parts, focuses on the Bologna Process and its repercussions for the work of European university professors. It emphasizes the intensification of the work of these professors. As has occurred in Brazil, influenced by the socalled "CAPES Evaluation and Support Model," European university professors are feeling the weight and effects of so called "academic productivism." The central and longest portion of the text presents an interview with Professor Joseph M. Blanch, of the Autonomous University of Barcelona (UAB). His reflections and revelations about the implementation of the Bologna Process at UAB in particular and at European universities in general, serves as an example of the implantation and the (pre)visualization of the results of a process characterized by heteronomy. A brief presentation is also made to present the issue and the context of the interview.

Key words: Bologna Process. Intensification of teaching work. Academic productivism.

\section{Contextualização da entrevista}

o ano de 2005, a convite de colegas de duas universidades portuguesas, proferi palestras sobre o processo de avaliação da pós-graduação (PG) stricto sensu no Brasil. O histórico da PG, o detalhamento dos critérios de avaliação e do financiamento e as estratégias de implementação do sistema nas universidades brasileiras, especialmente a partir da mudança que passou a vigorar em meados da década de 1990 (Bianchetti \& Sguissardi, 2009), provocavam reaçôes de estranheza entre os colegas lusitanos. Como é possível um sistema, um modelo de avaliação e financiamento centralizado, unificado, ser implementado de forma tão heterônoma e uniforme em todas as universidades?

Em um olhar retrospectivo, daria para afirmar que os desdobramentos do "Pacto" ou do "Processo" ou, simplesmente, de "Bolonha" ainda não se faziam sentir da forma como hoje se manifestam no contexto das universidades europeias. A "Declaração de Bolonha”, originalmente, foi um manifesto assinado pelos ministros da Educação dos 29 países $^{2}$ que, à época, em 19 de junho de 1999, pertenciam à União 
Europeia (UE). Certamente, para a maioria dos presentes nas palestras, o prazo de 10 anos para a concretização do "Espaço Europeu de Educação Superior" significava um tempo longo e as mudanças nas instituições não haviam sido, ainda, desencadeadas na extensão, profundidade e intensidade com que foram realizadas, na medida que a data-limite - 2010 - de implantação plena do "Processo" se aproximava. E mais: que se chegaria a um processo de unificação ou de "harmonização" dos currículos e outras convergências, como veio a acontecer.

A Europa, berço do modelo da universidade ocidental, e os europeus, em geral, sempre foram ciosos da sua criação e, em especial, do processo de construção da autonomia dessa instituição (Garcia, 2008; Amaral \& Magalhães, 2001, 2004) e da rica diversidade que caracterizava essas instituições entre os países que a compõem. Aqui está, provavelmente, uma das causas da demora em constatar como a "Declaração" iria impactar nas universidades europeias. As universidades - penso que podemos afirmar -, progressiva e independentemente de onde se localizem, estão cada vez mais semelhantes. Os ditames do mercado, o "managerialismo" (Santiago et al., 2005) e o Academic Capitalism (Slaughter \& Leslie, 1997; Slaughter \& Rhoades, 2004) estão na ordem do dia em um processo crescente de descaracterização da instituição, naquilo que lhe era historicamente inerente, e caminhando para uma "universidade mundial" (Sguissardi, 2005) ou para uma "nova ordem educacional" (Antunes, 2008). Indícios desse caminhar para uma uniformização podem ser apreendidos em diversas fontes. As coletâneas Universidade contemporânea. Políticas do Processo de Bolonha (Pereira \& Almeida, 2009), publicada no Brasil, e Toward a global $P h D$ ? Forces e forms in doctoral education worldwide (Nerad \& Heggelund, 2008), ${ }^{3}$ publicada simultaneamente nos EUA e na Europa, são uma indicação do quanto, ao invés de falarmos em "Espaço Europeu de Educação Superior" (EEES), seria mais acertado falar das iniciativas e das induções à criação de um "Espaço Mundial de Educação Superior".

À "Declaração" inicial seguiram-se reuniōes bienais (Praga, 2001; Berlim, 2003; Bergen, 2005; Londres, 2007; Leuven/Louvainla-Neuve, 2009) dos ministros da Educação dos países membros da UE, com o objetivo de avaliar o que havia sido feito e projetar a consolidação do EEES ou da "harmonização/convergência" entre os sistemas universitários dos diferentes países. No entanto, em termos de força 
propulsora à concretização do proposto no "Pacto", nada se compara ao acordado entre os países da UE na chamada "Agenda de Lisboa" (2000). Para além do diagnóstico sobre o quanto a UE estava perdendo em competitividade frente aos EUA ${ }^{4}$ - e logo seria agregada a China como novo rival -, visualiza-se na implementação de Bolonha, ou na apropriação da universidade, o meio mais adequado para (re)inserir ou transformar a Europa na "economia do conhecimento mais competitiva e dinâmica do mundo, antes de 2010". Percebe-se assim que, gradativamente, passamos do campo institucional, universitário, da educação, para o campo da economia, do mercado, das relações competitivas entre nações e blocos. E Bolonha é a estratégia por excelência para alcançar os objetivos da competitivade, ${ }^{5}$ da atratividade, da mobilidade, da empregabilidade e todos os demais objetivos que aparecem inoculados na apropriação mercadológica que se faz da "Declaração".

Seja nas entrevistas, seja na literatura, há uma concordância da necessidade de reforma ou "reconstrução" da universidade europeia. A discordância prende-se à mudança proposta e ao tempo de implementação. Os entrevistados referem-se à Bolonha como um processo permeado de "luzes e sombras", isto é, sob a capa de um discurso inovador, a perspectiva de mercado imiscui-se na universidade. As constatações são no sentido de que "el processo, hasta ahora tiende a ser unidireccional, de arriba hacial la base; debería ahora dar paso a un genuíno esquema bidireccional" (Ruiz, 2004, p. 33). Em outras palavras, consideram que a participação ou não houve, ou foi exígua. Os professores "não foram tidos e nem havidos nesse processo", segundo uma entrevistada portuguesa.

De acordo com Spiegl e Westphal (2008, p. 2), na Áustria, como na maior parte dos países europeus e nas universidades,

(...) a implantação do processo de Bolonha representou uma completa mudança paradigmática em função das diferenças nas estruturas académicas prévias. Esta mudança paradigmática não foi amplamente debatida antes da introdução do processo de Bolonha, apesar da mudança fundamental envolvida em cada país e cada sistema de educação universitária.

Tendo presente este contexto e com informações de que na UAB as discussões sobre a implementação de Bolonha tinham alcançado patamares elevados de debate (Liria \& García, 2009), optamos por realizar 
entrevistas nesta Instituição. Foi por meio destas que obtivemos dados mais detalhados a respeito das manifestações de alunos e de professores, com posicionamentos pró e contra o alinhamento da UAB às determinações de Bolonha.

Estes são os antecedentes do encontro com o professor Josep Blanch para a entrevista. Destaco que o roteiro de entrevista semiestruturada foi seguido no essencial, isto é, na busca de apreender os pontos de aproximação e distanciamento do modelo CAPES de avaliação e financiamento da PG no Brasil e a implementação de Bolonha na UE, particularmente no que diz respeito ao segundo e terceiro ciclos europeus, destacando-se questões referentes às temporalidades de formação e atuação dos entrevistados e a sua percepção sobre o processo de intensificação do trabalho na universidade.

\section{A entrevista}

Lucídio Bianchetti [LB] - Estamos na sala do prof. Blanch, na $U A B$, Espanha, dia 20 de outubro de 2009. A primeira questão relacionada-se à sua formação pós-graduada, o período - cronologicamente falando - e o tempo - cronologia e intensidade - em que fez seu curso, bem como sobre sua condição de orientando, tutorado, supervisionado ou, como vocês falam aqui, "dirigido".

Josep M. Blanch [JMB] - Comecei em uma época em que, em relação ao tempo, funcionávamos de outra maneira. Comecei uma tese doutoral sobre os estereótipos regionais espanhóis, inspirando-me na psicologia dos povos, de W. Wundt. ${ }^{6}$ Nesta pesquisa pretendia estudar como os autoestereótipos (que somos "nós") e os heteroestereótipos (que são "eles") se expressam através dos discursos das pessoas bêbadas. Então, o trabalho de campo consistia em ir a um bar, a uma hora da madrugada, e sentar ao lado de uma pessoa que me levava 15 copos de cerveja ou de vinho de vantagem. Isto me permitiu obter interessantes informações empíricas da metade da Espanha para baixo... Mas, quando fui ao norte do país, lá as pessoas tinham uma capacidade de resistência física ao vinho que eles podiam ter 20 copos no corpo e eu começava com um e, quando estávamos 25 a cinco, eu lhes contava minha vida e eles estavam numa boa. Coincidindo com a constatação da resistência física dessa gente, me encontrei com uma crescente resistência 
epistemológica e metodológica dos meus diretores de tese ${ }^{7}$ com respeito à temática e ao modo de a confrontar. Consideravam meu tema um arcaísmo e meu método inadequado, em uma época dominada pelo positivismo mais puro e duro, tanto na sociologia quanto na psicologia. Tive uma dupla pressão para abandonar o projeto. Naquelas circunstâncias, eu não estava capacitado ou em condiçôes de confrontar todo o sistema. Então, o que fiz foi mudar de projeto e de orientadores. E passei a me interessar pela psicologia da religião e da moral, tomando "Deus" como referente, como significante que, independentemente da realidade que haja atrás Dele, é uma força social e histórica capaz de "mover montanhas".

$\mathrm{LB}$ - Quando e onde fez seu doutorado?

JMB - Iniciei o doutorado em 1975. A defesa da tese foi em 1979, na Universidade de Barcelona.

$\mathrm{LB}-$ E como foi sua relação com os "diretores de tese"?

JMB - Quando da mudança, busquei dois diretores não-diretivos. E para mim foi perfeito, porque eu fiz a tese que eu quis e como quis, com muita autonomia. Os diretores leram a tese somente no final, quando estava quase concluída.

LB - E correu tudo bem com a defesa, com a banca, com o "tribunal de tesis"?

JMB - A temática foi avaliada como sendo "arqueológica" e "obsoleta”. Lamentavelmente, dois anos depois, a irrupção do fundamentalismo islâmico no Irã colocou em evidência que o tema não era tão extemporâneo como parecia. Da mesma forma, em relação ao primeiro projeto que tive que abandonar, a explosão de nacionalismos, nos anos de 1990, na esteira da fragmentação da antiga URSS e do que foi a federação Iugoslava, forneceu os motivos, os indicadores para pensar que a questão dos estereótipos não somente é pré-moderna, como também pós-moderna.

LB - Avançando um pouco na direção da nossa temática central: Defendida a tese, quando você começou a orientar?

JMB - Quase imediatamente, pois há 30 anos, na Espanha, havia poucos doutores em Psicologia. Então, comecei a fazer parte de bancas e a orientar teses. Aquele foi um tempo que lembro agora como maravilhoso, porque o tempo dos anos de 1980, inclusive 1990, funcionava 
de outra maneira. Agora estou orientando muitas teses on line. Quer dizer que as quatro da tarde me chega um e-mail com arquivo e as oito da noite chega-me outro, dizendo: "Você leu"? "Mas você, contudo, não me respondeu"! "Está você morto"? E, no terceiro dia, acabo por responder. Veja que, nos anos de 1980, orientei algumas teses de alunos latino-americanos. Estas teses iam a ritmo de barco. Isto quer dizer: o pessoal escrevia lá, com máquina de datilografia, e me enviava pelo correio postal. O barco demorava um mês para chegar; eu demorava um mês para abrir e tardava um mês em responder - manualmente - e enviava por barco, que acabava demorando um mês mais para chegar ao orientando, de forma tal que, num ciclo de um ano, havia duas interaçōes. E se a pessoa entrava em crise, tivesse um filho... assim pois, passava um ano sem trabalhar e a tese seguia, no seu tempo ajustado ao processo vital da pessoa.

LB - Aproveitando a brecha, diria então que hoje estamos lidando com outro conceito de tempo, outro tipo de exigência. E como você tem lidado com isso?

JMB - Procuro ser bom como pessoa e como orientador, eticamente responsável... sem consegui-lo, às vezes. Ocorre que, muitas vezes, estou cansado ou me encontro com doutorandos cansados ou com doutorandos impacientes no contexto de um sistema que impóe, de modo implacável, agenda e calendário, ritmos e prazos, protocolos e informes para as diferentes fases do processo da tese. Atualmente, procuro conciliar o próprio tempo de trabalho como orientador com o tempo dos orientandos e o tempo do sistema. É um grande desafio. Temos mais trabalho do que podemos fazer e sempre há circunstâncias que agravam o processo.

LB - Processa-se uma compressäo do tempo, sendo-se obrigado a fazer mais coisas em menos tempo?

JMB - Exatamente. É um tempo densificado e intensificado.

LB - E por falar em tempo, prazos, quantos anos são concedidos para fazer o doutorado?

JMB - Aqui agora são três anos, tendo em conta que Bolonha comporta um sistema de trabalho compacto, baseado na supervisão permanente do trabalho, em ciclos semestrais (de semestres de quatro meses). Em cada ciclo, orientando e orientador devem fazer uma espécie de rapport de como está se desenvolvendo o projeto e de como estão sendo cumpridos os objetivos programáticos do semestre... 


\section{$\mathrm{LB}-E$ esses relatórios são apresentados a quem?}

JMB - Para uma espécie de minibanca que supervisiona semestralmente o processo.

\section{LB - Nestes três anos!?}

JMB - Sim! E, então, como pode imaginar, este processo exige muito do orientador e do orientando.

$\mathrm{LB}-E$ o orientador tem que fazer isso com todos os seus orientandos?

$\mathrm{JMB}$ - Muitos rapports que supõem uma pressão administrativa muito forte.

$\mathrm{LB}-H a ́$, então, uma heteronomia neste processo.

$\mathrm{JMB}-\mathrm{E}$ cada vez mais crescente.

LB - Gostaria de retomar e aprofundar um aspecto: Por favor, faça sua análise do Processo de Bolonha e como este veio sendo discutido, aceito, incorporado e, também, rejeitado, aqui na UAB e, particularmente, no âmbito da Faculdade de Psicologia, na qual houve votação e predominou a decisão de rejeitar ou de não se inserir no Processo. E, para começar, pedir-lhe-ei que aborde o assunto em uma perspectiva mais macro, isto é, o que significou Bolonha para a Universidade espanhola e para as universidades da Europa?

JMB - Bolonha é agora mesmo um termo polissêmico, que não somente significa muitas coisas diferentes, mas que, inclusive, às vezes, significa coisas contraditórias. Em primeiro lugar, significa a primeira universitas que levou este nome, fundada na cidade de Bolonha no ano de 1088 . No ano em que se completava o $900^{\circ}$ aniversário da sua fundação, reitores de universidades europeias, reunidos naquela cidade, assinaram um Manifesto onde se resume o espírito universitário. Em 1999, os ministros da Educação assinaram a "Declaração de Bolonha". Em documentos como estes, se reatualiza a retórica sobre a universidade como espaço "universal" de reflexão, de liberdade de pesquisa, de expressão e de cátedra, de crítica, de autonomia com respeito aos poderes econômicos, políticos e ideológicos, de amor à verdade, à beleza e ao bem, à ciência e à sabedoria. Em segundo lugar, Bolonha significa um projeto de reorganização do ensino superior, de caráter global. Nesse sentido, a $D e-$ claração de Bolonha foi assinada por 46 países (30 deles pertencentes à UE e uma quinzena que "subiu" no trem de Bolonha). Este projeto tem uma dupla face: a manifestamente acadêmica, que pretende integrar, unificar e estandardizar o ensino superior europeu para facilitar a mobilidade 
dos estudantes, e a efetiva integração europeia ao nível universitário e do mercado de trabalho. E, também, tem uma face econômica, que consiste em tornar operativas as consignas e recomendações emanadas do BM, do FMI e da OMC, que, em nome da sustentabilidade financeira da universidade, propõem sutilmente a "economização", a mercantilização, a empresarialização e o gerenciamento da universidade, com o pretexto de que é necessário "modernizá-la", "desburocratizá-la" e "abri-la ao mercado". Porém, paralelamente a esta retórica, se vai introduzindo um discurso tecnológico e tecnocrático que vai impondo pautas, critérios e condiçôes financeiras, técnicas, materiais e culturais, colocando no centro do sistema valores como eficiência, produtividade, competitividade, rentabilidade, análise custo-benefício, avaliação por resultados, gestão por objetivos. Enfim, toda a retórica sobre a universidade sucumbe eclipsada por esta nova retórica economicista e managerialista, que vai entrando como por uma porta lateral. Em terceiro lugar, Bolonha significa também um produto final, em forma de modelo de organização universitária, de planos de estudo, de créditos, papéis, protocolos didáticos e de avaliação, conteúdos homologáveis etc. Em uma palavra: uma universidade boa e bonita (se supōe), barata (university "low cost", com menos anos, menores custos), rápida (uma espécie de "fast university", na qual se faça o mesmo em menos anos), estandardizada (universidade "McDonaldizada", mesmo formato em diferentes espaços), financeiramente sustentável (graduação barata e curta, rápida, para a massa, e mestrado pago para a elite) e mercantilmente adaptada. Dessa forma, em nome de uma universidade europeia pós-moderna, nos encontramos com professores e alunos trabalhando mais em menos tempo e com os mesmos meios.

LB - Agora você está falando das consequências do Processo de Bolonha na pós-graduação?

JMB - Não somente na pós-graduação. Também na graduação. Professores e alunos devemos fazer mais com menos tempo e com os mesmos recursos materiais, humanos e técnicos. Por exemplo, temo-nos convertido em professores - pesquisadores e também em magisters -, monitores, em professores que dão aulas magistrais durante o dia, e passamos as noites, os weekends e as férias "tutorizando" alunos desorientados, adeptos do Google. E fazemos tudo isso, ademais, com a impressão de que nos falta tempo em dois sentidos: nos falta tempo para fazer o trabalho e nos falta tempo para fazer bem o trabalho. E, portanto, há aí um problema de "má consciência profissional": trabalhando de dia e de 
noite, não faço o trabalho que tenho que fazer e não faço bem o trabalho que devo fazer. Um duplo motivo de intranquilidade como trabalhadores, associada à consciência de não estar cumprindo um dever moral de fazer bem todo o trabalho. E isto é um problema que passou pela primeira fase de individualização, isto é, "eu não sei gerenciar bem o meu tempo e nem minha carga de trabalho". Mas, depois, se descobre que é um problema generalizado e crescente entre todos os colegas implicados neste tipo de trabalho de educação superior e de um determinado grau de implicações e de responsabilidades institucionais. Então, estamos nisso. Bolonha foi uma grande promessa que gerou uma grande expectativa. Porém, nas universidades, introduziu-se de cima para baixo, como uma imposição política e tecnocrática. Não se discutiu, não se introduziu como elemento para debater desde a base do professorado e alunado. Os gestores da preparação da "cozinha do projeto" foram se tornando cada vez mais técnicos, cada vez mais especialistas na forma do que no conteúdo, cada vez mais pedagogos e não filósofos, no sentido mais profundo da educação; cada vez mais economistas e managers do que professores com sabedoria e experiência; nos encontramos cada vez mais dominados por um sistema que nos exige muito e nos concede muito pouco e que nos coloca permanentemente em conflito. Conflito entre o que nos mandam fazer e o que consideramos que deveríamos fazer; conflito entre os fins formativos e os meios logísticos; conflito na organização do próprio tempo como professores, pesquisadores, tutores e pessoas humanas e cidadãos com vida privada e familiar. O novo sistema de organização e de gestão converte-nos em administradores do nosso trabalho. Nossa relação com a universidade, com o Estado, com as entidades que financiam a pesquisa, com os colegas e com os estudantes é cada vez mais burocrática. Temos uma sobrecarga de trabalho na forma de tarefas administrativas que passamos, a cada dia, uma maior proporção do nosso tempo preenchendo papéis, papéis e certificados, respondendo a questionários, alimentando bases de dados insaciáveis, as quais, quanto mais informação lhes damos, mais nos exigem. Por outro lado, a demanda dos estudantes é cada vez mais exigente, mais diversa e mais complexa. Exigem bolsas de estudo; exigem cartas de recomendação; certificados de avaliação; exigem sessões virtuais ou acompanhamento virtual e, como a vida é muito cara e a maior parte dos nossos orientandos são alunos que moram muito tempo nos seus países de origem (não espanhóis), muito trabalho 
presencial é substituído por trabalho virtual. Neste contexto, nem sempre se produzem os efeitos de uma combinação virtuosa de trabalho virtual e dos necessários efeitos do trabalho presencial, cara a cara, olhando nos olhos, tocando-se o braço, animando-se, tomando café - café real, não café virtual! Então, muitos dos efeitos positivos do trabalho tradicional até os anos de 1980 se estão perdendo pela falta de tempo, de condições, de espaço para compartilhar. E isso gera, de um lado, ambivalências com o novo sistema e, por outro lado, o que se chama "nostalgia acadêmica" daqueles longos almoços, com prolongados cafés, nos quais, entre colegas, éramos solidários e intercambiávamos informações, ideias, livros etc. Eu me lembro de, há muitos anos, quando tínhamos poucos livros e precisávamos fazer muitas viagens a Paris, Londres, para buscar livros. Eu ia com uma mochila. E como conhecia os temas de interesse dos meus colegas, trazia livros para mim, mas também para todos os colegas. E, de outra parte, todos traziam livros para mim. Porque todos conheciam meus campos de interesse, sobre que temática estava lendo, pesquisando, publicando e ninguém tinha problemas de competitividade comigo para dizer: "Não, este vai competir comigo para uma bolsa ou o que quer que seja". Agora, a gente acaba sabendo o que faz um colega, vizinho de sala, em um congresso internacional ou entrando no Google. Porém, não temos tempo para tomar um café...

LB - Você traça um quadro realistico, humana e academicamente triste, muito próximo daquilo que estamos há algum tempo experienciando no âmbito universitário brasileiro. Agora, gostaria que focalizasse um pouco a questão da resistência a este quadro, particularmente o movimento de oposição à implementação de Bolonha, a partir do episódio de negativa da Faculdade de Psicologia da UAB, de aderir às determinaçôes institucionais pro-Bolonha.

JMB - Há ciclos políticos nas políticas da Universidade e na participação dos estudantes e professores na vida pública acadêmica e na política acadêmica. Depois de um período de uma certa passividade e falta de participação, estamos em um ponto alto, um pico de participação, de cunho bastante radical, antissistema em todos os aspectos do domínio político e inclusive do sistema acadêmico. Num contexto de imposição pelo sistema de fatos acadêmicos consumados, gerou-se uma dinâmica maniqueísta: "pró” versus "contra” Bolonha. Ou se está totalmente contra ou totalmente a favor. E Bolonha é algo muito mais complexo, que tem, indubitavelmente, componentes positivos, que representa também uma oportunidade excelente em muitos aspectos e que comporta 
muitos riscos e ameaças. Mas não temos conseguido encontrar-nos em um contexto favorável para um debate sereno. Nos primeiros anos, Bolonha foi um assunto de especialistas que gestionavam e lançavam diretrizes e nos obrigavam a desenhar programas de gestão por competências, objetivos didáticos e créditos ECTS. ${ }^{8}$ E quando chegou a hora do debate, passou a ser feito em um momento de crise, de urgência histórica, de falta de pressupostos, de falta de serenidade. E este contexto está mais exacerbado em uns países do que em outros. Porém, aqui na Espanha, está acontecendo em um contexto de uma certa reemergência de grupos relativamente radicais que tomam o protagonismo no movimento estudantil e em algum movimento do professorado. Neste contexto houve manifestações de rua e ocupaçôes de faculdades, reaçōes de decanatos e de reitorias, que enviam a polícia para desalojar estudantes que ocuparam um espaço institucional... ação-reação, expedientes acadêmicos, reações dos estudantes etc. Em maio de 2009, numa reunião/ assembleia da minha faculdade (Psicologia), a totalidade dos estudantes e uma parte dos professores, do pessoal da administração, uniram seus votos para impor democraticamente o "não" à aprovação do "plano de estudos", condição necessária para a plena implementação do plano Bolonha nesta faculdade. Foi um "não" sem plano de viabilidade sobre quem gere o mesmo "não". Para os partidários do "não", isso é simplesmente um não a Bolonha. Para os partidários do "sim", isso significa sair do trem da história, ficar na marginalidade acadêmica, política e econômica, perder o "trem Bolonha" e não ter outro "trem" para pegar. Uma espécie de suicídio institucional. De maio a outubro, no decorrer de uns meses "fora do trem", que está a toda a velocidade, avaliaram-se os efeitos perversos do "não" e as implicações de um "sim" condicionado (in extremis). Grupos de professores elaboraram um "plano de aplicabilidade" de Bolonha na faculdade e traçaram cenários com perspectivas futuras de gestão do "sim". Finalmente, numa reunião de faculdade, em outubro, depois de um longo debate, aprovou-se o plano e a Faculdade de Psicologia subiu de novo no "trem Bolonha".

LB - Então, daria para dizer que os confrontos acabaram se precipitando, uma vez que a data-limite, o ano de 2010, como o prazo final para a implantação das diretrizes de Bolonha está aí...

JMB - Sim. Em 2010, Bolonha tem que estar implementada. Mas, para isso, as universidades e as faculdades têm que cumprir uma série de protocolos de planos de estudos e docentes, tanto no doutorado, 
como no mestrado e na graduação. E aqui temos programas de mestrado e doutorado que estão funcionando segundo o modelo de Bolonha - isto é, se começou a construir a casa da cobertura para baixo! Mas quando se tratou de implementar o plano da graduação sob o modelo de Bolonha, a Faculdade de Psicologia conseguiu manter-se seis meses resistindo a fazê-lo nas atuais condiçóes.

LB - Então, na UAB, a autonomia universitária, em geral, e das unidades, em particular, propicia as condiçôes para que algumas votem "sim" $e$ outras "não" em assuntos...

JMB - Exatamente, no que concerne a assuntos de competência das faculdades, como a elaboração dos planos de estudos (conteúdos programáticos) e docentes (quem faz o quê), condições básicas para organização operativa do curso acadêmico.

$\mathrm{LB}-E$ isto é respeitado?

$\mathrm{JMB}$ - O sistema respeita e as unidades têm que se defrontar com consequências das suas decisões.

LB - Pelas suas respostas e reflexões, a impressão que se tem é que resta à universidade aderir ou... aderir. Se o orçamento está amarrado à adesão à Bolonha, o próprio conceito de autonomia é implodido. Somente recolocando: na sua opinião, não há mesmo saída a não ser aderir? A resistência não faz mais sentido? É extemporânea?

JMB - Desde a lógica política e tecnocrática que caracteriza o Plano Bolonha, um "não" não é racional, não é razoável, não é viável... Em resumo, não é operativa a gestão do não. Frente a isto é que se pode dizer que ou é "sim" ou é "sim".

LB - Agora voltando-nos à dinâmica de como eram organizados os cursos e como o serão a partir da implementação de Bolonha. Detalhadamente, antes os cursos das áreas de humanas e sociais duravam de quatro a cinco anos. Depois vinha o mestrado e o doutorado. Como é que vai funcionar a partir de agora, com a perspectiva de se "acomodar" às diretrizes de Bolonha?

JMB - Um dos problemas que Bolonha pretendia resolver e que está em processo de resolver era superar uma enorme heterogeneidade de modelos de planos de estudo que, em um país ou em uma mesma universidade, em uma mesma carreira, eram diferentes: Psicologia, Medicina ou Odontologia, por exemplo. Em um país poderia se exigir 
O Processo de Bolonha e a intensificação do trabalho na universidade...

nove anos para uma carreira, em outro sete, em outro quatro, em outros três. Em um a especialidade era graduação e em outro era licenciatura. E, então, isto implicava que a Europa, com um mercado de trabalho unificado (onde legalmente os trabalhadores de um país podem trabalhar em outro país), os "colégios profissionais" (as organizaçôes corporativas de defesa dos interesses profissionais) negavam ao pessoal de outros países a licença para trabalhar como profissionais nos seus países, porque um currículo obtido em um país “não” era homologável para trabalhar em outro. Então, esta era uma contradição e tudo se tornava impossível. Por exemplo, se os odontólogos belgas tinham uma carreira de quatro anos, os espanhóis cinco, os italianos cinco, os portugueses três... Frente a isso, o órgão de classe dos odontólogos de um país podia dizer que somente os odontólogos deste país poderiam trabalhar, pois os outros ou saberiam demais, ou saberiam pouco. Então, havia corporativismo em nível de nação que impedia o desenvolvimento de um espírito europeu de comunidade ou de unidade de mercado de trabalho e, também, de mercado de titulações. Também outro objetivo de Bolonha era tornar homologáveis os planos de estudo que permitissem que a Europa se tornasse universal, de maneira que os estudantes pudessem estudar um semestre em Roma, um em Paris, um em Londres, um em Barcelona etc. Isso teoricamente seria possível. O sistema de créditos ECTS seria este facilitador da mobilidade intraeuropeia. E este sistema de computação estandardizado, que permite homologação automática de estudos feitos em qualquer país europeu, também permite uma melhor interlocução com países não europeus. Isto é, pode haver uma única maneira de falar com o Brasil, por exemplo, para que os estudantes brasileiros que façam intercâmbios saibam que o mesmo tratamento vão lhe dar em Dublin, em Atenas ou Barcelona. Então, essa ideia de facilitar a integração e mobilidade pela via da estandardização é boa! Em geral, nos planos de estudo de cada especialidade, dos 100\% dos conteúdos, 70\% vêm de Bolonha, 20\% vêm do país e $10 \%$ vêm da universidade ou do próprio centro ao qual o professor e o aluno estão vinculados. É claro que há uma variedade no que diz respeito a opçôes, matérias que se frequenta dentro da especialidade ou particularidades de campos do saber. Mas tudo isso está dentro de uma lógica de muita racionalidade, inclusive racionalidade técnica. Alguns países, inclusive, tinham a possibilidade de articular a graduação e o mestrado, de tal maneira que definiram três anos de graduação, dois de 
mestrado e três de doutorado. Outros optaram pelo esquema quatro mais um. Se o sistema é quatro mais um ou três mais dois, pouco importa. No final, são cinco anos que acabam sendo a base para o doutorado. Tudo isso está ok! Mas passar de um sistema "antigo", baseado na docência, magistral, de uma universidade mais do tipo alemã e francesa, universal, enciclopédica, de muitos conteúdos, para um modelo mais de tipo anglo-saxão, onde o centro de referência passa a ser o aluno e não o professorado, é algo complexo. Os créditos ECTS se contam não mais em hora-professor (referência básica do sistema baseado no "ensino" do professor), mas em horas-aluno (referência retórica do sistema baseado na "aprendizagem" do aluno). Um crédito antigo significava 10 horas-professor, mais ou menos. Agora, um crédito novo passa a ser 25 horas-aluno, que, dependendo das matérias, podem ser sete horas-professor, 10 horas de trabalho de campo e oito horas de biblioteca; dependendo do tipo de matéria (disciplina) ou conteúdo, se é mais teórica, mais prática ou experimental. Então, esta é uma mudança de concepção. O problema é que o professor, antigamente, sabia que dava 10 horas-aula e preparava 10 horas-aula e ia para casa ou ia para a sua sala e atendia os alunos que vinham procurá-lo, um a um. Agora, tem que ocupar suas 10 horas aula, mais dirigir o trabalho de campo, mais dirigir o trabalho de biblioteca e mais consultar as dúvidas dos alunos pela internet... tudo isso!

LB - Temos aí, então, a evidência da intensificação, da sobrecarga a que está submetido o professor neste novo modelo.

JMB - Exatamente. E sobre isso eu calculo que, jogando muito por baixo, a passagem do sistema moderno ao pós-moderno, do sistema antigo ao sistema Bolonha, suponho - falando do meu campo de atuação - um acréscimo de, no mínimo, mais 30\% de trabalho, o que, evidentemente, deveria implicar mais $30 \%$ em meios, recursos humanos, técnicos e materiais, isso sem contar a diferença do tempo linear e diacrônico da "tese que viajava de barco" nos anos de 1980 e o tempo que é sincrônico e instantâneo, do arquivo que "viaja" pela internet. Sem dúvida, a tecnologia e a forma como está sendo utilizada incrementaram enormemente o ritmo e a intensidade do trabalho. Temos assim, então, que Bolonha imprime, incorpora uma pressão adicional de, pelo menos, uns 30\%. Na retórica afirmava-se que, com a adesão à Bolonha, haveria, como contrapartida, recursos financeiros, técnicos e materiais. Porém, na verdade, Bolonha foi um plano ambicioso, pensado 
em tempos de "vacas gordas" e deve ser executado em tempos de "vacas magras". Nestes tempos de crise, o plano deve ser implementado a "custo zero". Os meios hoje disponíveis são insuficientes, tornando muito mais forte o descompasso entre discurso e realidade. Então, há razões técnicas, econômicas, financeiras, pessoais, corporativas, pedagógicas etc. que se vão somando, provocando um sentimento de incômodo que leva a que se afirme: "bom, há trabalho demais e aqui continuamos os mesmos e com condiçôes mais precárias". Este é o primeiro motivo de desconforto por parte de muitos professores. Depois, há outras razões, mais de tipo ideológico, mais ou menos fundamentadas: "Bolonha abre as portas à privatização, à 'economização' e à mercantilização" etc.; mudou o sistema de valores, de maneira que os valores técnicos predominam sobre os humanistas; os valores de cálculo custo-benefício são prioritários em relação a valores teóricos ou filosóficos. A criação ou eliminação de especialidades vêm dadas mais por critérios mercantis do que por critérios acadêmicos. A "ética”, como disciplina e como conteúdo, uma vez que o mercado não a pede, deve desaparecer dos planos de estudo. E se o mercado exige, por exemplo, massagens ou hamburguer etc., então virão faculdades para atendê-lo. Portanto, o mercado está introduzindo uma nova racionalidade na universidade; o aluno se converte em cliente e consumidor e, consequentemente, o professor em vendedor de produtos e serviços, em um "agente de vendas" que tem que pensar mais na satisfação do cliente do que em outros critérios. Então, está desaparecendo o professor exigente, uma vez que os professores são avaliados em função da satisfação dos alunos e estes, raramente, avaliam bem um professor muito exigente. Podem considerar um professor muito bom, mas preferem um que atribua "excelente" na avaliação e exija menos. Está mudando o perfil, a identidade; estão sendo gerados conflitos éticos. Assim, o professor é colocado frente a dilemas como este: "Exijo o que acredito que devo exigir ou me acomodo a um sistema no qual eu, como professor individual, contribuo para que o meu departamento ganhe pontos se fabricamos titulados e temos uma baixa taxa de fracasso acadêmico por perda de alunos ou por repetição de cursos etc.!?”. Claramente, está havendo uma mudança de valores.

\section{$\mathrm{LB}-E$ isto vale, se aplica à pós-graduação stricto sensu também?}

JMB - Vale para todos! Se calculamos que um aluno, para entrar na pós-graduação, está ocupando um espaço público, usando meios públicos, com custos públicos, com benefícios privados e públicos, 
supõe-se que este aluno tenha que aproveitar esta oportunidade no tempo que se lhe concede. De maneira que, se não o fizer, perde a oportunidade e tem que voltar para o fim da fila, e tem que recomeçar o processo. Então, isto, por um lado, introduz racionalidade e elimina casos de alunos parasitas que passavam anos e anos na universidade sem fazer nada; mas, de outro, gera uma pressão que, em últimos termos, pode ser negativa para os alunos e para o sistema mesmo. Porque, veja, por exemplo: eu pude mudar de tema de tese sem que isto viesse em detrimento da qualidade da minha formação. Apenas mudei de temática e inclusive isso me permitiu que, em relação à minha tese, quando já tinha o aval dos meus orientadores, eu tenha tido a opção de postergar um ano a defesa, pois não estava satisfeito com o resultado e quis aprofundá-la mais, adicionando um novo capítulo. Isto hoje seria impensável.

LB - E esta decisão foi tomada sem que dela resultassem prejuizos à instituição, para os orientadores e para você?

JMB - Exatamente. E, assim, eu pude apresentar uma tese tranquilamente e frente à qual eu estava razoavelmente satisfeito. Diferentemente de agora, que há muitos fatores de pressão. Então, os efeitos perversos hoje tornam-se mais visíveis, uma vez que aparecem alguns tipos de teses doutorais com um desenho típico de quem quer fazer uma tese com o mínimo de tempo possível, com o mínimo esforço, mínimo desgaste, porém que seja adequada a um perfil de tese estandardizada e aprovável. Com isso, é certo que se faz mais facilmente uma tese sobre burnout, sobre o qual há 800 mil artigos (e, portanto, com valor auferido perto do zero), do que sobre um tema inovador, mas cuja pertinência pode ser discutida. Então, na escolha dos temas, na escolha das equipes, no desenho dos projetos, compulsoriamente, opta-se por projetos com uma vida máxima de três anos. Portanto, não há projetos de longo prazo. O longo prazo desapareceu do horizonte.

LB - E por falar nesta questão de tempo, presente nas diretrizes de Bolonha, relacionada à redução dos anos de escolarização, na graduação $e$ na PG, não há aqui uma contradição? Em outras palavras, o reduzido número de empregos ou postos de trabalho acaba fazendo com que a permanência por mais tempo na universidade seja vista como uma estratégia para manter o estudante ocupado. Tenho inclusive uma orientanda fazendo uma pesquisa de doutorado sobre a continuidade dos estudos como equivalente a 
O Processo de Bolonha e a intensificação do trabalho na universidade...

emprego [cf. Mattos, 2007], mesmo que sob o signo da precariedade. Então, se se reduz o tempo de estudo, de permanência na universidade, não acaba se ampliando a pressão sobre ou no chamado mercado de trabalho, uma vez que se passa a contar com mais egressos titulados em menos tempo, embora seja possivel questionar a qualidade da formação ou das titulaçôes?

JMB - Sim. Sim. (longa pausa). Eu diria que se sacrifica a qualidade em nome da quantidade, da economia e da eficiência. E mais, diria que a ilusão dos tecnocratas que desenharam o sistema é a de que os alunos que são capazes de trabalhar sob pressão e que conseguem concluir sua graduação e PG são os mais capazes, competentes, empregáveis... Porém, há outra razão econômica de fundo: no velho plano de estudos, o Estado financiava, para cada aluno, uma carreira ou um tempo de estudo de cinco anos (licenciatura), que representavam, também, para alguns estudantes, um longo tempo de refugio seguro contra o desemprego, ou um pretexto legítimo de não inserção no mundo do trabalho. Hoje, o Estado renuncia a manter "estudantes ocupados" fora daquele mundo e opta por fabricar estudantes "empregáveis", isto é, capazes de abrir seus espaços no mercado de trabalho. Com o Plano Bolonha, o Estado somente financia uma graduação barata de três anos. $\mathrm{Na}$ sequência, o aluno deve financiar-se um mestrado, caro, de dois anos. Os mestrados devem ser autossustentáveis com o dinheiro aportado pelas inscrições e pelas anuidades. Então, a partir da implementação de Bolonha, o Estado põe menos dinheiro no financiamento dos alunos e na universidade.

LB - Bom, o tempo da entrevista está se esgotando, porém gostaria de levantar uma última questão. Você já tocou no assunto, mas pergunto: não lhe parece que as chamadas novas tecnologias vieram trazer algumas vantagens em termos de economia de tempo? Veja, se antes era necessário deslocar-se para fazer uma pesquisa, para ter acesso a um documento a ser consultado ou, como você disse, "fazer a viagem de barco", agora é possivel consultar uma base de dados em instantes. Como conciliar essas vantagens - reais ou supostas - com a pressão que acaba se abatendo sobre professores e discentes, em função da diminuição do tempo para fazer tudo o que precisa ser feito?

JMB - Evidentemente, o que você coloca faz pensar na economia de tempo e meios que permitem alcançar os objetivos que antes eram impossíveis de se conseguir. Mas o efeito combinado de todas essas 
vantagens é que o pessoal tem muito menos tempo; o tempo é muito mais denso e intenso e a impressão que se tem é de que o tempo escapa e de não fazermos bem o próprio trabalho por falta de tempo. Esta impressão é cada vez mais forte. Portanto, aqui falha algo. Veja, datilografei/digitei a minha tese na máquina de escrever antiga... daquelas que permitiam pouco mais de 40 toques por minuto, e sem outros dispositivos técnicos para corrigir o texto que não fosse o tip-ex, letra a letra, com o risco de ter que voltar a começar a folha se a correção terminasse em buraco na folha de papel. Quando surgiu o computador, cheguei a imaginar que passaria a ter a solução para todos os meus problemas tradicionais. E, no início, cheguei a ter um, dois, três, quatro, cinco computadores em minha casa. Depois passei a quatro, três, dois, um... e agora procuro trabalhar na sala da universidade. O computador, em casa, permite teletrabalhar de dia e de noite, fazer mais trabalhos e trabalhar mais e melhor, porém com custos à qualidade de vida pessoal. Trabalhando com internet, por exemplo, receber um e-mail é percebido como melhor do que nenhum, três é melhor do que um; dez é melhor do que um, 20 é melhor do que dez? Hum! Já tenho minhas dúvidas: 60 é melhor do que 20? Já tenho claro que não. Hoje, recebo diariamente mais de 100 e-mails em média, dos quais 20 são claramente spam, 20 são perfeitamente não urgentes, 20 são claramente destes que dá para esperar, mas que, com certeza, tenho que responder em uma semana, e 40, dos quais 20 são extremamente urgentes e 20 podem esperar somente dois ou três dias e, além do mais, trazem arquivos incorporados, muito volumosos. E minha experiência é que alguns dias venho trabalhar na universidade às $9 \mathrm{~h}$ da manhã e, às $9 \mathrm{~h}$ da noite, acabei tendo saído somente para almoçar, pois os novos emails que vieram entrando na parte superior da tela são mais numerosos do que aqueles que fui respondendo ou deletando. Então, a impressão de impotência, de olhar-se no espelho e perceber a própria expressão de perplexidade é cada dia mais frequente, forte e generalizada. Isso é o que aparece na minha pesquisa atual sobre a "sujeitivação" das condiçóes de trabalho pelo pessoal sanitário que trabalha em hospitais e pelo pessoal acadêmico que trabalha em universidades (pessoal que, até os anos de 1980, figurava no topo das categorias dos profissionais mais satisfeitos com seu trabalho). Alerto que utilizo o neologismo "sujeitivação" em um duplo sentido: como sujeição ("sujeição" ou "sujeitação") e de subjetivação ("apropriação subjetiva” de uma realidade 
exterior, "construção subjetiva" ou da "subjetividade"), entendendo que o segundo sentido, às vezes, tem muito do primeiro. É o caso da "subjetivação" de Bolonha como "sujeitação" a um protocolo "sim ou sim"). Nesta pesquisa, perguntamos a pessoas como eu (e imagino que como você), que estamos já neste nível de (sobre)demanda do trabalho, como elas fazem frente a situações como esta. Então, estamos descobrindo certas formas de (micro)resistência, que podem se materializar de muitas maneiras. Por exemplo, resistências que eu utilizo [risos]... por favor, não as comente com ninguém.... ainda de maneira não de todo refletida, porém que as utilizo certamente de modo estratégico: alguns e-mails, simplesmente os deixo "morrer". Alguns outros, particularmente quando faço viagens ao exterior, não os leio. Eu tenho três níveis de correio, três endereços eletrônicos que correspondem a três planos de interaçôes: um, absolutamente privado; outro semipúblico para os colegas, grupos de pesquisa etc. e outro que é totalmente público. É neste último que recebo em torno de 100 mensagens diárias. Precisamente, neste mais público, estando no exterior, tenho (afortunadamente) certas dificuldades objetivas de acesso e de gestão. Então, utilizo este pretexto e quando regresso posso ter milhares de e-mails acumulados e mensagens me dizendo: "você tem o servidor saturado", "você tem que limpar" etc. Então, às vezes, eu mando um e-mail dizendo: "eu sinto muito, estava no estrangeiro e tive problemas..." etc. Quanto aos outros que tenho que responder, defronto-me com vários problemas. Eu procuro honestamente respondê-los, mas, quando estou mais do que cansado, devo também me preocupar com minha saúde física e mental. Assim, num contexto em que habitualmente sacrifico parte da minha saúde, da minha vida privada, dos meus prazeres, ao altar do trabalho, por que não lhe sacrificar também alguns e-mails? Confesso que, algumas vezes, demoro muito tempo para responder alguns e-mails e isto não faz sentirme bem, porém tenho preferido conviver com este desconforto do que me sentir vítima de um sistema que não me protege. Então, eu tenho que desenvolver estratégias de autodefesa ativa e estou tentando inovar neste campo. Primeiro, estou tentando convencer meus colegas de que o fato de me mandarem um e-mail não lhes dá garantia absoluta que obtenham retorno de minha parte, porque já estou em um ponto de superação do limite da capacidade da resposta pessoal às demandas que recebo, com os atuais recursos de que disponho para confrontá-las. E peço compreensão. De outra parte, dentro desta questão das (micro)resistências, encontrei 
colegas que são mais assertivos: por exemplo, definiram que somente vão responder 500 e-mails por semana. A partir do 501, deletam. E, na segunda-feira, começam do zero. Alguns outros, o que fazem é dedicar duas manhãs por semana a responder o correio eletrônico, e tudo o que supera este tempo não respondem ou deletam... Bom, por falar em tempo, chegou a hora do outro compromisso.

LB - Realmente, é uma pena não podermos continuar, pois esses dados, atitudes, posturas, reflexöes contribuem muito para tornar mais presente uma situação vivida pelos trabalhadores da educação. Muito obrigado pelo tempo disponibilizado para discutirmos estas questôes que tratam do tempo e da forma como o estamos ou não gerindo. Em breve, vou enviar-lhe um email para ver em qual categoria estou classificado...

\section{Notas}

1. Doctor en Psicología y diplomado en Ciencias Sociales; catedrático de Psicología Social Aplicada en la Universidad Autónoma de Barcelona; exdecano de la Facultad de Psicología y director del Departamento de Psicología de la Salud; director del Máster en Rehabilitación Psicosocial en Salud Mental; autor de numerosas publicaciones sobre la dimensión psicosocial de la experiencia de cambio sociolaboral; pesquisador visitante extranjero en Brasil, con bolsa CNPq. Projecto de Investigación - 2007-2010: "El capitalismo organizacional como factor de riesgo psicosocial. Efectos psicológicos colaterales de las nuevas condiciones de trabajo dictadas por el capitalismo académico y sanitario implantado en universidades y hospitales no lucrativos de la red pública" (investigación internacional financiada por Ministerio Educación y Ciencia).

2. Em termos de UE, no ano de 2009, soma 46 o número de países que aderiram ao Processo de Bolonha.

3. Nesta coletânea estão inseridos textos que apresentam experiências exitosas de "Doctoral Education" em todos os continentes, com destaque para alguns países. Renato J. Ribeiro, ex-diretor de Avaliação da CAPES, participa da coletânea, relatando o histórico da atuação e perspectivas desta Agência.

4. Dados da UNESCO mostram que, "em 2000, os rendimentos obtidos pelos Estados Unidos graças ao acolhimento de estudantes estrangeiros foram avaliados pela OCDE em 10,29 mil milhões [10,29 bilhões] de dólares (...). Além disso, este país lidera os países que atraem o maior número de estudantes estrangeiros (...)." (Bindé, 2007, p. 151).

5. Conforme Amaral (2005, p. 41), “o que está por detrás de Bolonha é o problema da competitividade europeia num sistema globalizado e não a criação de uma área de ensino superior competitiva. O que está por detrás de Bolonha são os problemas dos salários europeus muito elevados, agravados pelo que resta do sistema do Estado/Providência, os quais prejudicam a posição da Europa na nova economia global".

6. Referência ao alemão Wilhelm M. Wundt (1832-1920), considerado o "pai” da psicologia experimental.

7. Na Espanha, o orientador é denominado "director de tesis".

Educ. Soc., Campinas, v. 31, n. 110, p. 263-285, jan.-mar. 2010

Disponível em <http://www.cedes.unicamp.br> 
O Processo de Bolonha e a intensificação do trabalho na universidade...

8. Referência ao European Credits Transfer System, alternativa que faculta aos alunos frequentarem aulas ou atividades transformáveis em créditos em qualquer universidade que tenha aderido ao Processo e diplomar-se por uma delas. Para Blanch, "o sistema de créditos ECTS seria este facilitador da mobilidade intraeuropeia".

\section{Referências}

AMARAL, A. Bolonha, o ensino superior e a competitividade económica. In: Serralheiro, J. (Org.). O Processo de Bolonha e a formação dos educadores e professores portugueses. Porto: Profediçōes, 2005.

AMARAL, A.; MAGALHÃES, A. On markets, autonomy and regulation the Janus Head revisited. Higher Education Policy, London, n. 14, p. 7-20, 2001.

AMARAL, A.; MAGALHÃES, A. Epidemiology and the Bologna saga. Higher Education, Amsterdam, v. 48, p. 79-100, 2004.

ANTUNES, F. A nova ordem educacional: espaço europeu de educação e aprendizagem ao longo da vida. Coimbra: Almedina, 2008.

BIANCHETTI, L.; SGUISSARDI, V. (Org.). Dilemas da pós-graduação: gestão e avaliação. Campinas: Autores Associados, 2009.

BINDÉ, J. (Coord.). Rumo às sociedades do conhecimento; relatório mundial da UNESCO. Lisboa: Instituto Piaget, 2007.

GARCIA, M.G.F.P.D. Autonomia universitária e avaliação da qualidade do ensino universitário. Lisboa: Universidade Católica, 2008.

LEMINSKI, P. Metamorfose: uma viagem pelo imaginário grego. São Paulo: Iluminuras, 1999.

LIRIA, C.F.; GARCÍA, C.S. El plan Bolonha. Madrid: Catarata, 2009.

MATTOS, V.B. Pós-graduação em tempos de precarização do trabalho: um estudo sobre o alongamento da escolarização entre os mestrandos da UFSC. 2007. Dissertação (Mestrado) - Programa de Pós-Graduação em Educação, Universidade Federal de Santa Catarina, Florianópolis.

NERAD, M.; HEGGELUND, M. (Ed.). Toward a global PhD?: forces e forms in doctoral education worldwide. Seattle: University of Washington, 2008. 
PEREIRA, E.M.A.; ALMEIDA, M.L.P. (Org.). Universidade contemporânea: políticas do Processo de Bolonha. Campinas: Mercado de Letras, 2009.

RIBEIRO, R.J. Doctoral education in Africa, South America and Mexico. In: NerAd, M.; Heggelund, M. (Ed.). Toward a global PhD?: forces e forms in doctoral education worldwide. Seattle: University of Washington, 2008. p. 131-145.

RUIZ, R. El Proceso de Bologna, cuatro años después (Una evaluación del área europea de educación superior). Pro-Posiçôes, Campinas, v. 15, n. 3, p. 21-36, set./dez. 2004.

SANTIAGO, R.; MAGALHÃES, A.; CARVALHO, T. O surgimento do managerialismo no sistema de ensino superior português. Coimbra: Fundação das Universidades Portuguesas; CIPES, 2005.

SGUISSARDI, V. Rumo à universidade mundial: e a universidade será feita a sua imagem e semelhança. In: SGUISSARDI, V.; Franco, M.E.D.P.; MorosinI, M.C. Internacionalização, gestão democrática e autonomia universitária. Brasília, DF: INEP, 2005. p. 7-28. (Textos para discussão, 20).

SLAUGHTER, S.; LESLIE, L.L. Academic capitalism: politics, policies and the entrepereneurial university. Baltimore: Johns Hopkins University, 1997.

SLAUGHTER, S.; RHOADES, G. Academic capitalism and the new economy: markets, State and higher education. Baltimore: John Hopkins University, 2004.

SPIEGL, A.; WESTPHAL, E. The Bologna Process: a challenge to the Austrian universities. In: Froment, E.; Kohler, J.; Purser, L. (Ed.). EUA Bologna Handbook: making Bologna work. Berlin: Raabe, 2008. p. 2-3. 